\title{
Long-term outcomes after pulmonary endarterectomy
}

\author{
Fabio Dardi, Alessandra Manes, Daniele Guarino, Sofia Martin Suarez, Antonio Loforte, \\ Mariangela Rotunno, Davide Pacini, Nazzareno Galiè, Massimiliano Palazzini
}

Alma Mater Studiorum, University of Bologna and IRCCS Sant'Orsola University Hospital, Bologna, Italy

Correspondence to: Fabio Dardi. Alma Mater Studiorum, University of Bologna and IRCCS Sant'Orsola University Hospital, Bologna, Italy. Email: fabio.dardi@aosp.bo.it.

Submitted Sep 29, 2021. Accepted for publication Oct 21, 2021.

doi: 10.21037/acs-2021-pte-179

View this article at: https://dx.doi.org/10.21037/acs-2021-pte-179

Chronic thromboembolic pulmonary hypertension $(\mathrm{CTEPH})$ is a form of pulmonary hypertension $(\mathrm{PH})$ that is potentially curable with pulmonary endarterectomy (PEA). PEA is considered the first-line treatment as it can remove the chronic, fibrotic, flow-limiting organized thrombus within the pulmonary arterial bed, addressing the primum movens of CTEPH. In fact, after successful PEA, there is rapid reverse remodeling (usually within 2-3 weeks) of the right ventricle (RV) resulting in reduced volume and increased ejection fraction. As RV function is a major determinant of prognosis in $\mathrm{PH}$, it is easy to understand the impact of PEA on long-term outcome of CTEPH patients; in most registries the 3-, 5- and 10-year post-operative survival is $84-92 \%, 76-86 \%$ and $72-77 \%(1-6)$, respectively. This is significantly higher than the survival of patients with inoperable CTEPH, which in most registries is $70 \%$, $50-59 \%$ and $40 \%$ at 3,5 and 10 years, respectively $(2,6)$. Moreover, when compared to the general population, the life expectancy following PEA is shorter, but the difference is quite small (2), and prognosis may be primarily related to comorbidities as half of long-term follow-up deaths are attributable to conditions other than RV failure (3).

Nevertheless, we cannot simply consider PEA as a cureall. First of all, PEA has an in-hospital mortality that is, in high-volume centers, less than 5\% (1,6,7). Secondly, $10 \%$ to $50 \%$ of patients (according to the different definitions utilized) may have persistent $\mathrm{PH}$ after surgery (3) and this can impact long-term outcomes, reducing exercise capacity (8) and, in some clinical records, survival as well $(5,6,8)$. The severity of persistent $\mathrm{PH}$ that seems to be prognostically relevant is still debated. However, the cutoffs of 34-38 $\mathrm{mmHg}$ of mean pulmonary arterial pressure (mPAP) and of 5.3-7.3 Wood units (WU) of pulmonary vascular resistance (PVR) after PEA seem to be predictive of death $(3,5)$. Thirdly, symptoms of reduced exercise tolerance may persist after PEA regardless of residual $\mathrm{PH}$ and may require up to 1 year to recover despite the immediate hemodynamic improvement (7). A possible explanation is that the normalization of the hemodynamic profile at rest may not be translated into an immediate functional recovery of the pulmonary vascular bed (9). In addition, comorbidities can play an important role; PEA performed in octogenarians results in a similar 5-year survival rate as compared to patients a decade younger, but the improvements in cardiac index and functional capacity are blunted in the elderly (10). Finally, recurrent CTEPH after normalization of pulmonary hemodynamics by PEA can occur. It is a very uncommon event (around 1\%) and can be related to recurrent acute embolic events that occur in $<2 \%$ of patients (preferentially in those with inferior vena cava filters and/or antiphospholipid syndrome or in patients with inadequate anticoagulant therapy) or related to progression of distal pulmonary arterial disease over time $(3,7)$.

In our experience between 2003 and 2020, 170 patients with CTEPH (median age of 63 years) underwent PEA. The Kaplan-Meier (KM)-estimated 3-, 5- and 10-year survival rates were $88 \%$ [95\% confidence interval (CI): $82-92 \%$ ], $87 \%$ (95\% CI: $80-91 \%$ ) and $75 \%$ (95\% CI: 66-82\%), respectively. Survival was significantly better than for the cohort of 173 inoperable CTEPH patients (median age of 73 years) treated with medical therapy; the KM-estimated 3-, 5- and 10-year survival rates were 84\% (95\% CI: $78-89 \%$ ), $72 \%$ (95\% CI: $63-79 \%$ ) and $39 \%$ (95\% CI: 29-49\%), respectively. We arbitrarily split our cohort into two timeframes, before and after 2011, to 
consider the surgical learning curve and assess whether there has been an improvement in outcome over time. The in-hospital mortality for the early cohort was $15 \%$ and the 5 -year survival rate was $83 \%$ (95\% CI: $73-89 \%$ ); the inhospital mortality for the late cohort was $5 \%$ and the 5 -year survival rate was 91\% (95\% CI: 80-96\%). Conditional 3-, 5- and 10-year KM-estimated survival for patients surviving the in-hospital post-operative period was $99 \%$ (95\% CI: 94-100\%), 97\% (95\% CI: 92-99\%) and 84\% (95\% CI: 74-90\%), respectively. In the early cohort, conditional 5 -year survival was $97 \%$ (95\% CI: $90-99 \%$ ), and in the late cohort, it was 96\% (95\% CI: 84-99\%). Forty-three percent of patients discharged from hospital have persistent $\mathrm{PH}$ (defined as a mPAP $\geq 25 \mathrm{mmHg}$ and $\mathrm{PVR} \geq 3 \mathrm{WU}$ at 6 months after PEA) and $61 \%$ of them received $\mathrm{PH}-$ specific drugs $(18 \%$ of the latter were also treated with balloon pulmonary angioplasty). No statistically significant difference in conditional 5-year survival was observed between patients with or without persistent $\mathrm{PH}$ after surgery $(\mathrm{P}=0.225)$, or between patients with persistent $\mathrm{PH}$ treated or not with $\mathrm{PH}$-specific drugs $(\mathrm{P}=0.802)$. However, patients with persistent $\mathrm{PH}$ after PEA treated with $\mathrm{PH}-$ specific drugs have significantly higher median (interquartile range) mPAP $\{34$ [30-43] vs. 29 [26-32] $\mathrm{mmHg} ; \mathrm{P}<0.001\}$ and PVR [5.2 (4.3-6.8) vs. 3.5 (3.3-4.5) WU; $\mathrm{P}<0.001]$. Thus, it can be speculated that $\mathrm{PH}$-specific treatment may have improved the prognosis of those patients with a worse hemodynamic profile.

In conclusion, PEA is the gold standard of care for patients with CTEPH deemed operable as it can provide excellent long-term outcomes with low mortality rates in high-volume centers. However, a favorable long-term outcome is not only dependent on a successful intervention, but is also related to the post-operative management of PEA-treated patients; a close clinical follow-up aimed at maintaining proper anticoagulation and monitoring the long-term clinical, functional and hemodynamic effects of PEA is mandatory. In fact, in the event of residual PH, additional strategies should be considered to potentially target both distal pulmonary vasculopathy (with $\mathrm{PH}$ specific drugs) and residual chronic thrombotic lesions in subsegmental arteries (with balloon pulmonary angioplasty). However, the degree of residual $\mathrm{PH}$ requiring treatment has yet to be clearly defined.

\section{Acknowledgments}

Funding: None.

\section{Footnote}

Conflicts of Interest: The authors declare no conflicts of interest.

Open Access Statement: This is an Open Access article distributed in accordance with the Creative Commons Attribution-NonCommercial-NoDerivs 4.0 International License (CC BY-NC-ND 4.0), which permits the noncommercial replication and distribution of the article with the strict proviso that no changes or edits are made and the original work is properly cited (including links to both the formal publication through the relevant DOI and the license). See: https://creativecommons.org/licenses/by-nc-nd/4.0/.

\section{References}

1. Mahmud E, Madani MM, Kim NH, et al. Chronic Thromboembolic Pulmonary Hypertension: Evolving Therapeutic Approaches for Operable and Inoperable Disease. J Am Coll Cardiol 2018;71:2468-86.

2. Kallonen J, Glaser N, Bredin F, et al. Life expectancy after pulmonary endarterectomy for chronic thromboembolic pulmonary hypertension: a Swedish single-center study. Pulm Circ 2020;10:2045894020918520.

3. Cannon JE, Su L, Kiely DG, et al. Dynamic Risk Stratification of Patient Long-Term Outcome After Pulmonary Endarterectomy: Results From the United Kingdom National Cohort. Circulation 2016;133:1761-71.

4. Tromeur C, Jaïs X, Mercier O, et al. Factors predicting outcome after pulmonary endarterectomy. PLoS One 2018;13:e0198198.

5. Skoro-Sajer N, Marta G, Gerges C, et al. Surgical specimens, haemodynamics and long-term outcomes after pulmonary endarterectomy. Thorax 2014;69:116-22 .

6. Delcroix M, Lang I, Pepke-Zaba J, et al. Long-Term Outcome of Patients With Chronic Thromboembolic Pulmonary Hypertension: Results From an International Prospective Registry. Circulation 2016;133:859-71.

7. Jenkins D, Madani M, Fadel E, et al. Pulmonary endarterectomy in the management of chronic thromboembolic pulmonary hypertension. Eur Respir Rev 2017;26:160111.

8. Miyahara S, Schröder TA, Wilkens H, et al. Longterm Outcomes After Pulmonary Endarterectomy in 499 Patients Over a 20-Year Period. Ann Thorac Surg 2021;111:1585-92.

9. Su J, Hughes AD, Simonsen U, et al. Impact of pulmonary 
endarterectomy on pulmonary arterial wave propagation and reservoir function. Am J Physiol Heart Circ Physiol 2019;317:H505-16.

10. Grazioli V, Ghio S, Pin M, et al. Pulmonary

Cite this article as: Dardi F, Manes A, Guarino D, Suarez SM, Loforte A, Rotunno M, Pacini D, Galiè N, Palazzini M. Long-term outcomes after pulmonary endarterectomy. Ann Cardiothorac Surg 2022;11(2):172-174. doi: 10.21037/acs2021-pte-179 endarterectomy in the octogenarian population: safety and outcomes. J Cardiovasc Med (Hagerstown) 2021;22:567-71. 